\title{
Fault Analysis of Grid Connected Photovoltaic System
}

\author{
Prakash Kumar Hota ${ }^{1, ~ *, ~ B a b i t a ~ P a n d a ~}{ }^{2}$, Bhagabat Panda ${ }^{2}$ \\ ${ }^{1}$ Department of Electrical Engineering, Veer Surendra Sai University of Technology, Burla, India \\ ${ }^{2}$ School of Electrical Engineering, KIIT University, Bhubaneswar, India
}

Email address:

p_hota@gmail.com (P. K. Hota)

${ }^{*}$ Corresponding author

\section{To cite this article:}

Prakash Kumar Hota, Babita Panda, Bhagabat Panda. Fault Analysis of Grid Connected Photovoltaic System. American Journal of Electrical Power and Energy Systems. Vol. 5, No. 4, 2016, pp. 35-44.doi: 10.11648/j.epes.20160504.12

Received: August 16, 2016; Accepted: September 3, 2016; Published: September 29, 2016

\begin{abstract}
A new method of current control strategy for grid connected photovoltaic (PV) system is presented in this paper. The connection of photovoltaic system with the grid is a difficult task as the solar irradiation is a nonlinear quantity. The objective of this work is to develop a model of the photovoltaic system with maximum power point tracking (MPPT) system connected to $11 \mathrm{KV}$ grid by implementing new control technique so that maximum active power transfer from PV to grid can be taken place without injection of harmonics. The considered system consists of a PV system, MPPT controller, boost converter, voltage source inverter (VSI), 3- $\Phi$ filter, a control system, a distribution network, load and grid. In the beginning, a model of a photovoltaic array was developed and then a MPPT controller and a direct current to direct current (DC-DC) converter are designed. To connect PV system to grid, a power electronics converter is needed which can convert DC voltage into three- phase AC voltage. Three-phase VSI using insulated gate bipolar transistors (IGBTs) is used. By means of a step-up transformer and filter, this three-phase VSI is connected to the distribution network. The proposed control of the three-phase grid-connected solar PV system is designed in the synchronously-rotating $d$ - $q$ reference frame. Here, $V_{d c}$ is measured, then compared with $V_{d c r e f}$ and accordingly the error is fed to proportional-integral (PI) controller from which $I_{d r e f}$ is generated. As PV system should inject only active power, so reactive power injected to grid is made zero by making $I_{q r e f}$ zero. There after the final model is simulated by using MATLAB/SIMULINK and different output waveforms are analyzed for different conditions. Finally the fault analysis is carried out to observe the behavior of the system.
\end{abstract}

Keywords: Grid-connected PV System, MPPT, Voltage Source Inverter (VSI), PWM Technique, LLLG Fault, MATLAB/Simulink

\section{Introduction}

Recently Govt. of India has started focusing more on renewable energy source addition into the distribution network. In India there is enormous shortage of power and at the same time, there are ample possibilities of PV solar application, grid connected and off-grid both. Dense population and high solar insolation are the two factors that provide a good compounding for generation of solar power in India. Ministry of New and Renewable Energy is accountable for growth of renewable energy in India. In early 1980s it was set up, which was first in the world. Renewable Energy connected to grid capacity in India has reached $29.9 \mathrm{GW}$, of which wind constitutes $68.9 \%$, while solar PV produces around $4.59 \%$ of the renewable energy installed capacity. In recent years, as the demand for the need of electric power is increasing, the work regarding grid connected PV system has increased rapidly. The photovoltaic cell produces pollution less electricity. It requires almost no maintenance and has long lifespan. Nowadays, the photovoltaic is one of the most promising power markets in the world because of these advantages. Nevertheless, PV power is quite costly, and the reduction of cost of PV systems is contingent on wide research. From the standpoint of power electronics, this target can be reached by boosting up the output energy of a given PV array. This can be done by using power electronics converter.

Many research papers have been published on this technology considering various control strategies for threephase systems. Various authors have proposed different 
approaches to modeling and simulation of photovoltaic arrays. A novel approach for solar module temperature estimation using a simple diode model has been described by Farivar, et al. [1]. Schonardie, et al. [2] have applied $d q 0$ transformation on the three-phase grid connected PV system with active power control. Cai, et al. [3] have analyzed and simulated the grid connected photovoltaic PV systems using MATLAB. A control methodology has been proposed by Yazdani, et al. [4] and characterization of dynamics for a photovoltaic system interfaced with a distribution network has also been made. Blaabjerg, et al. [5] have presented an overview of control and grid synchronization for distributed power generation systems. Sunny, et al. [6] have discussed the harmonics control and performance analysis of a gridconnected photovoltaic system. Some of the advantages that have given below motivate the grid-connected photovoltaic system applications. These are (i) Cost reduction of the PV panels [7], (ii) Operation is pollution free (it does not harm any eco-system) [8], (iii) Capability to supply AC loads and (iv) Photovoltaic system injects active power to the grid and also relieving the demand of the grid (distributed generation). In addition, one of the most significant advantages is the possibility to accomplish a reactive power control originated from linear and non-linear loads that is connected to the system. This fact looks very attractive, so a single system is able to analyze the following two different functionalities such as (i) Energy generation to supply AC loads and (ii) Active filtering. Kjaer, et al. [9] described about different inverter topology used for grid connected PV system along with their advantages and limitations. Carrasco, et al. [10] have given a survey of power electronics equipments used for PV system required for grid connection. Enslin, et al. [11] have demonstrated the harmonic interaction between a large number of distributed power inverters and the distribution Network. Srisaen, et al. [12] described the effect of PV gridconnectedsystem location on a distribution system. A rigorous study and implementation of synchronization algorithm in three-phase grid connected system has been described by Naik, et al [13].Teng, et al [14] have studies on harmonic and reactive current detection in grid-connected PV power stations. Grid voltage monitoring techniques for single-phase grid connected solar PV system have been proposed by Lakshmanan, et al [15]. Pattanaik, et al [16] have discussed the design, simulation and performance evaluation of three-phase grid connected PV panel.

A new method of current control strategy of grid connected PV system is presented in this paper. The objective of this work is to develop a model of the photovoltaic system with maximum power point tracking (MPPT) system connected to $11 \mathrm{KV}$ grid by implementing new control technique so that maximum active power transfer from PV to grid can be taken place without injection of harmonics. The proposed control of the three-phase grid-connected solar PV system is designed in the synchronously-rotating $d-q$ reference frame. Here, $V_{d c}$ is measured then compared with $V_{d c r e f}$ and accordingly the error is fed to PI controller from which $I_{d r e f}$ is generated. As PV system should inject only active power, so reactive power injected to grid is made zero by making $I_{\text {qref }}$ zero. There after the final model is simulated by using MATLAB/SIMULINK and different output waveforms are analyzed for different conditions. Finally the fault analysis is carried out to see the behavior of the system.

\section{Proposed Methodology}

The proposed method is based on the controlling of current, active power and reactive power injected to the grid. The total system consist of a PV panel, MPPT controller, boost converter, three-phase voltage source inverter, sinusoidal filter, step-up delta/star transformer, distribution network, phase locked loop, $d q$-abc transformation block, PWM generator, distribution network, load and grid. The 305 Solar Panel is being chosen for modeling and simulation using MATLAB. Three-phase inverter converts $1200 \mathrm{~V}$ of constant DC voltage which is the output of boost converter into sinusoidal A.C voltage of magnitude $800 \mathrm{~V}$, then a stepup delta/star transformer is used to boost voltage up to 11 $\mathrm{KV}$. A phase locked loop (PLL) is used to track the phase angle which is required by the $d q-a b c$ transformation leakage block. Again the signal is transformed back to $a b c$ reference frame and that is fed to the PWM generator which provides pulse for grid connected $\mathrm{PV}$ inverter. $\mathrm{L}$ and $\mathrm{R}$ represent the transformer resistance and reactance. $L_{1}$ and $R_{1}$ represent the distribution network resistance and inductance. In the following sections each subsystem of the proposed methodology are described individually. The Fig. 1 given below illustrates the block diagram of grid-connected photovoltaic inverter.

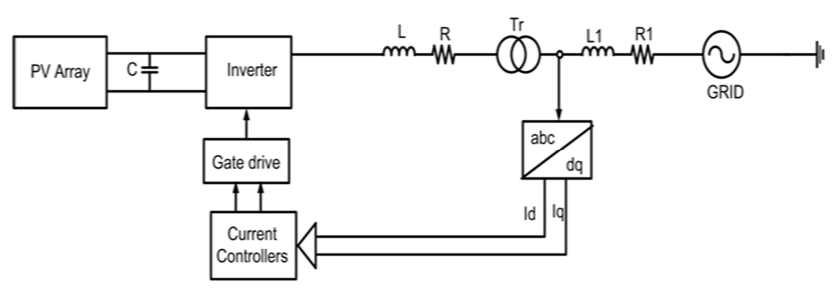

Fig. 1. Block diagram of the proposed system.

\section{Solar PV System}

Solar cells are the basic constituents of photovoltaic panels. Maximum solar cells are manufactured using silicon and also other materials are employed. Solar cells have property of photoelectric effect, where some semiconductors have capability of changing electromagnetic radiation precisely to electrical current. The charged particles produced by using incident radiation are distinguished smoothly to develop an electrical current by using suitable layout of the solar cell. The electricity generated by solar cell depends on the intensity of sunlight. When the incidence of sunlight is perpendicular to the front side of PV cell, the power generated by the solar cell is optimum. The basic fundamental element of a solar photovoltaic system is a solar cell. They are connected in series and parallel to constitute PV module and array. A single 
solar cell is mainly a combination of one current source, a diode and two resistors. The basic equivalent circuit of solar PV system is presented in Fig. 2.

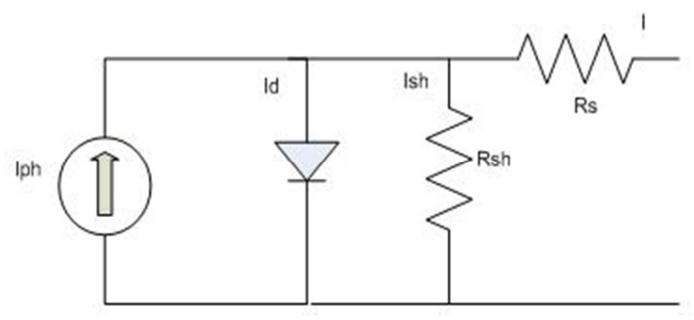

Fig. 2. Single diode model of a solar cell.

Where, $I_{p h}$ is the current produced by the photoelectric effect, $I_{d}$ is the diode current and $I_{s h}$ is the current through shunt resistance. $R_{S}$ and $R_{s h}$ are inherent resistances in series and parallel associated with the cell. Applying Kirchhoff's law of current, the terminal current of the cell is:

$$
\begin{gathered}
I=I_{p h}-I_{d}-I_{s h} \\
I_{p h}=I_{r} * I_{s c} / I_{r 0} \\
\left.I_{s}=I_{s c} \backslash \exp \left(V_{o c} /\left(a V_{t}\right)\right)-1\right] \\
I_{d}=I_{s} *\left[\exp \left(\left(V+I R_{s}\right) /\left(a V_{t}\right)\right)-1\right] \\
I_{s h}=\left(V+I R_{s}\right) / R_{s h} \\
V_{t}=k T N_{s} / q
\end{gathered}
$$

The light generated current or photo current is related to irradiance and temperature and the light current measured at some reference conditions. Then Final equation developed is:

$$
I=I_{p h}-I_{s}\left[\exp \frac{\left(V+I R_{s}\right) q}{a k T N N_{s}}-1\right]-\frac{V+I R{ }_{s}}{R_{s h}}
$$

Where, $I_{s}$ is the reverse saturation current, $N_{s}$ number of cells connected in series, $q$ is the electron charge, $k$ is Boltzmann's constant and $a$ is the ideality factor modified. In MATLAB/SIMULINK the PV array is modeled by using these above equations [1].

The Fig. 3 illustrates the I-V and P-V characteristic curves of photovoltaic module. As the PV equations are nonlinear, so the I-V and P-V characteristic curves are also nonlinear in nature. Therefore, from Fig. 3 it can be summarized that the irradiation level regulates the output current of solar cell, while temperature regulates the output voltage of solar cell.

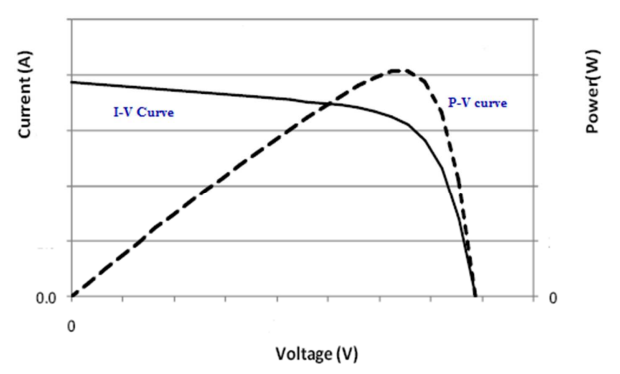

Fig. 3. I-V \& P-V characteristics of solar module.
The 305 Solar Panel is being chosen for modeling and simulation using MATLAB [1], whose parameters are shown in Table 1.

Table 1. Specifications of PV panel.

\begin{tabular}{ll}
\hline Temperature & $25{ }^{\circ} \mathrm{C}$ \\
Open circuit voltage, $\mathrm{V}_{\mathrm{oc}}$ & $64.2 \mathrm{~V}$ \\
Short circuit current, $\mathrm{I}_{\mathrm{sc}}$ & $5.96 \mathrm{~A}$ \\
Voltage at MPP, $\mathrm{V}_{\mathrm{mpp}}$ & $54.7 \mathrm{~V}$ \\
Current at MPP, $\mathrm{I}_{\mathrm{mpp}}$ & $5.58 \mathrm{~A}$ \\
Maximum power, $\mathrm{P}_{\max }$ & $70 \mathrm{KW}$ \\
Temperature coefficient of $\mathrm{I}_{\mathrm{SC}}, \mathrm{K}_{\mathrm{I}}$ & $3.5 \mathrm{~mA} /{ }^{\circ} \mathrm{C}$ \\
Temperature coefficient of power, $\mathrm{K}_{\mathrm{P}}$ & $-0.38 \% /{ }^{\circ} \mathrm{C}$ \\
\hline
\end{tabular}

\section{Boost Converter and MPPT Techniques}

As the output voltage of PV array is very low, so a step-up converter is necessary to increase the level of the PV voltage. DC-DC converter can be employed as switching mode regulator used for modifying uncontrolled dc voltage to a controlled dc output voltage. At fixed frequency controlling is normally accomplished by PWM and the switching device. The boost converter operates in two modes. During Mode I when the switch is closed, the current rises gradually through inductor and the diode D is off during this interval. During Mode II when switch is opened, the current flows through inductor, diode, capacitor and the load. The switch has a duty ratio $D$ which is defined as

$$
D=\frac{t_{\text {on }}}{t_{\text {on }}+t_{\text {off }}}=\frac{t_{\text {on }}}{T}
$$

The relation between the output and input voltage of the converter is as follows.

$$
\frac{V_{o}}{V_{S}}=\frac{1}{1-D}
$$

The switching of the DC-DC is regulated by using different MPPT techniques. MPPT is a method where some devices are employed for tracking maximum power. The most widely used maximum power point tracking method is Perturb and Observe (P\&O) or hill climbing method which has been considered in this work. P\&O MPPT algorithm is implemented very easily. It is based on the principle that when the voltage of operation of the PV array is varied in a given direction and the power extracted from the PV array increases, this suggests that the operating point has shifted toward the MPP and then the operating voltage must be changed in the same direction until the power drawn from the PV array decreases and so the operating point has deviates away from the MPP and hence, the direction of perturbation of operating voltage should be inverted. The Fig. 4 shows the schematic diagram of boost converter. 


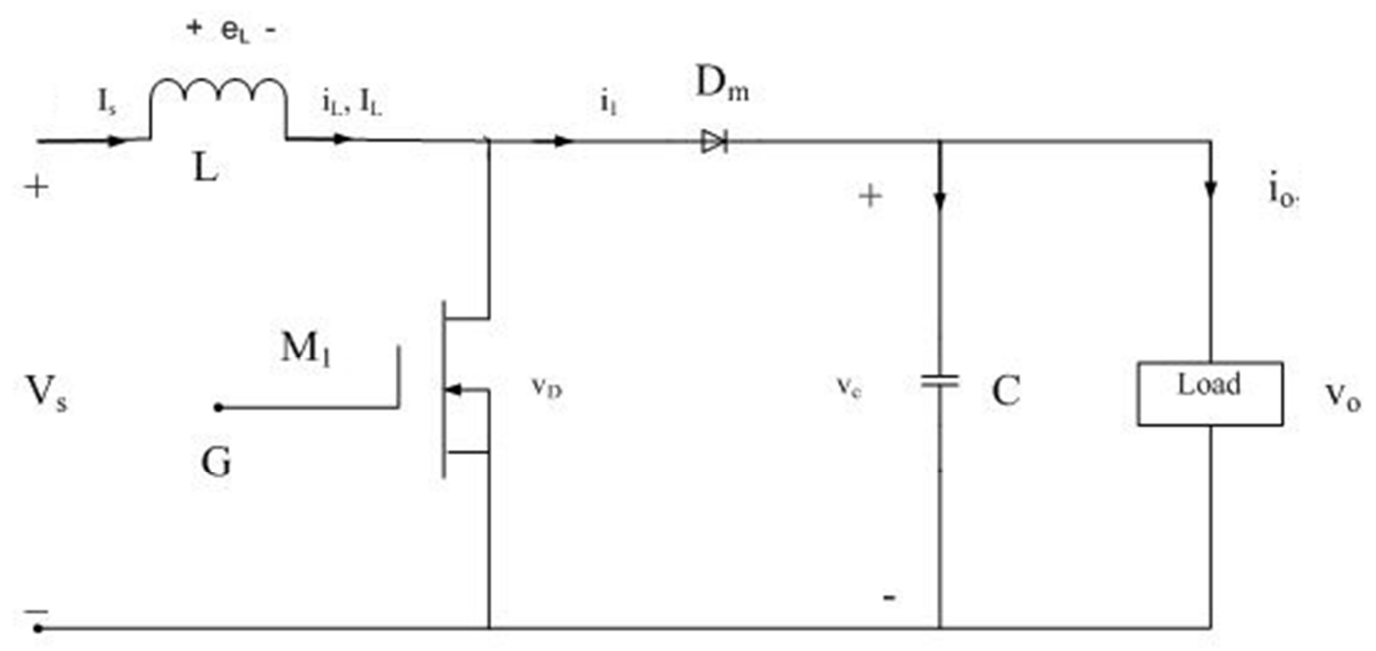

Fig. 4. Schematic diagram of boost converter.

\section{VSI and its Control Techniques}

Broadly inverters are of two types (i) CSI (current source inverter) and (ii) VSI (voltage source inverter) according to voltage and current requirements in the load end. Except some specific load, most of the applications require constant voltage supply. Hence, VSI is more often used and wellknown. Grid-connected 3- $\Phi$ inverters are normally VSIs. It can provide constant voltage in output end and maintain the load torque.

\subsection{Control Techniques}

$\mathrm{PV}$ panel is connected to the ac grid which is maintained at $11 \mathrm{KV}$ via a common DC/AC inverter. Inverters must produce higher voltage than the grid to assure power flow to the grid.So, PV inverter needs more attention from control point of view. PWM techniques are used for switching of the Inverter.The control strategy applied to the grid-side converter consists mainly of two cascaded loops. Usually, there is a fast internal current loop, which regulates the grid current, and an external voltage loop, which controls the dclink voltage.

\subsection{DC-link Voltage Control Scheme}

The Fig. 5 shows block diagram of dc-link voltage control scheme. Here, $u_{\text {dref }}$ which is the reference DC voltage tracked by the MPPT controller according to the maximum power point. Then, reference value compares with the actual DC voltage $u_{d c}$ and the error signal is fed to the PI controller. Then the PI controller generates the $i_{d r e f}$ the reference current value of $d$-axis component. This reference current value is passed through the current controller to generate actual $d$-axis current $i_{d}$ and then $\left(i_{p v}-i_{d}\right)$ is passed through integrator which generates $u_{d c}$.

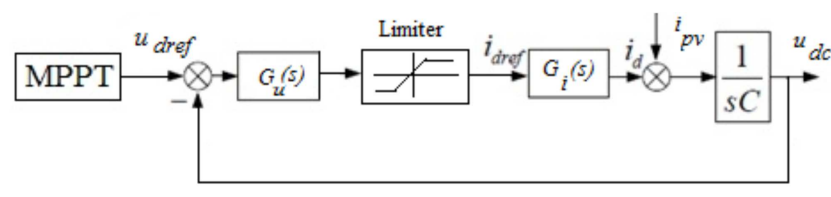

Fig. 5. Block diagram of DC link voltage control scheme.

$$
\begin{gathered}
u_{d c}=\frac{1}{c} \int i_{c} d t \\
u_{d c}=\frac{1}{c} \int\left(i_{p v}-i_{d}\right) d t \\
u_{d c}(s)=\frac{1}{C s}\left[i_{p v}(s)-i_{d}(s)\right] \\
i_{d}(s)=\frac{1}{T s+1} i_{d r e f}(s) \\
i_{d r e f}(s)=G_{u}(s)\left[u_{d r e f}(s)-u_{d c}(s)\right]
\end{gathered}
$$

Where, $C$ is the DC link capacitance, $i_{c}$ is capacitance current, $i_{P V}$ is the photovoltaic current, $u_{d c}$ is the DC link voltage, $u_{\text {dref }}$ the reference DC voltage, $i_{d}$ is $d$-axis component of grid current, $i_{\text {dref }}$ is its reference value.

\subsection{Current Control Scheme}

In the given control scheme, because of the control action the output current of the inverter follows a specified reference signal. This is achieved by transforming the threephase output currents of the inverter to the rotating reference frame $(d q 0)$ and then again converting them to the desired value. Here the system is assumed as a balanced system. So by using Park's transformation theory the $a b c$ component of output currents injected by the inverter are converted into three constant DC variables named as the direct, quadrature and zero variables $I_{d}, I_{q}$ and $I_{0}$, respectively. From this $d q$ transformation the constant DC quantities are obtained which can be easily controlled by using proportional-integral (PI) controllers. 


$$
\left[\begin{array}{l}
I_{d} \\
I_{q} \\
I_{0}
\end{array}\right]=\sqrt{\frac{2}{3}} \times T \times\left[\begin{array}{l}
I_{a} \\
I_{b} \\
I_{c}
\end{array}\right]
$$

By using the above formula, the transformation between two frames is done where $T$ is the transformation matrix. Since, the grid voltage is uncontrollable the most possible way of controlling the operation of the system is done by controlling $I_{d}$ and $I_{q}$ that are flowing to the grid. Fig. 6 shows that the control signal $U_{d}$ is the output of the controller processing the error signal:

$$
e_{d}=i_{\text {dref }}-i_{d}
$$

Similarly, $U_{q}$ is the output of another controller processing the error signal:

$$
e_{q}=i_{\text {qref }}-i_{q}
$$

The error signals are passed through the PI controllers. The PI controller constants are chosen as per following equations.

$$
\begin{aligned}
& K_{P}=\frac{L}{\tau_{i}} \\
& K_{i}=\frac{R}{\tau_{i}}
\end{aligned}
$$

Where, $\tau_{i}$ is time constant of the current control loop. The switching frequency of the inverter is $2 \mathrm{kHz}$ and the time constant $\tau_{i}$ is set to be ten times smaller than the switching time. $R$ and $L$ represent the total resistance and inductance of the distribution network. The Fig. 6 shows block diagram of current control scheme for controlling $I_{d}$ and $I_{q}$ that are flowing to the grid.

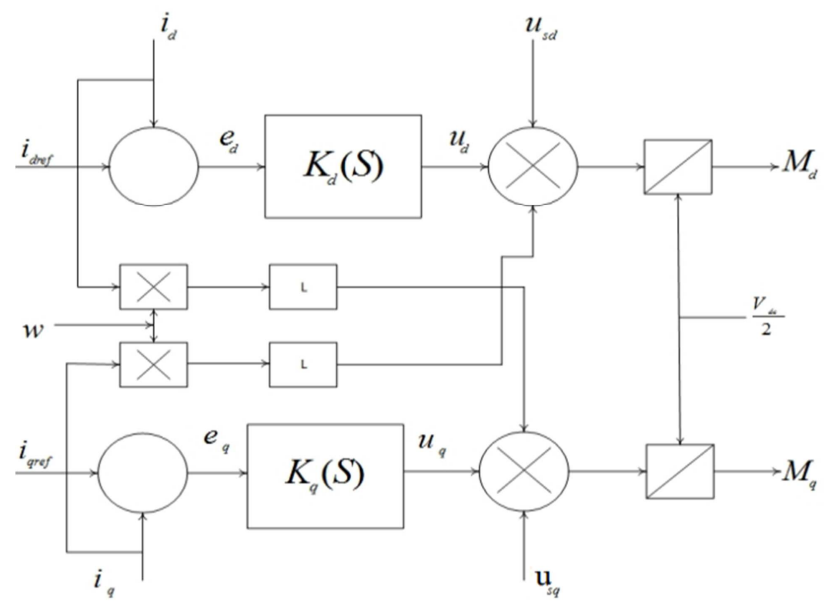

Fig. 6. Block diagram of current control scheme.

The PWM modulating signals are generated by using the equations:

$$
\begin{aligned}
& m_{d}=\frac{2}{V_{d c}}\left[U_{d}-L \omega i_{q}+U_{s d}\right] \\
& m_{q}=\frac{2}{V_{d c}}\left[U_{q}+L \omega i_{d}+U_{s q}\right]
\end{aligned}
$$

Where, $m_{d}, m_{q}$ are $d$-axis and $q$-axis components of modulating signals, $V_{d c}$ is the DC link voltage, $U_{d} \& U_{q}$ are $d$ axis and $q$-axis control signals, $U_{s d}, U_{s q}$ are the $d$-axis and $q$ axis components of VSI filtered voltage, $\omega$ is the grid angular frequency.

The PWM modulating signals are generated by transformation of $d$ and $q$ signals into $a, b, c$ and the gating pulses for the VSC valves are sent out. By controlling the values $m_{d}$ and $m_{q}, i_{d}$ and $i_{q}$ rapidly track their respective reference commands $i_{\text {dref }}$ and $i_{\text {qref }}$. Then active and reactive outputs of PV system are expressed as:

$$
\begin{gathered}
P_{s}=\frac{3}{2} U_{s d} i_{d} \\
Q_{s}=-\frac{3}{2} U_{s d} i_{q}
\end{gathered}
$$

Where, $P_{s}, Q_{s}$ are the active and reactive power injected to the grid, respectively.

As active power is dependent on the current $I_{d}$, so to inject real power to the grid, $I_{d}$ must be regulated to follow a specified reference signal $I_{d r e f}$, reactive power injection to the grid was set to zero and thus $I_{\text {qref }}=0$. The voltage $V_{P V}$ and current $I_{P V}$ of the PV arrays are used for calculating the inverter real power output delivered to the grid. In accordance with IEEE recommended practice for utility interface of PV system (IEEE Standard: 929-2000), most of the PV inverters designed for utility-interconnected service operate close to unity power factor. For a unity power factor, the command $I_{\text {qref }}$ is set to zero.

\section{Simulation Results and Fault Analysis}

Simulation studies are performed on grid connected PV implemented with proposed PWM techniques in MATLAB/Simulink. The results obtained from the simulations are taken with some specific values of the parameters. The Fig. 7 shows the Simulink diagram of the proposed system. In this paper, a $11 \mathrm{kV}$ grid integrated PV system is simulated. At $1000 \mathrm{~W} / \mathrm{m}^{2}$ solar irradiance the PV array delivers a maximum power of $70 \mathrm{~kW}$. At $1000 \mathrm{~W} / \mathrm{m}^{2}$ solar irradiance, the PV array generates voltage of about $321 \mathrm{~V}$. The $V_{o c}, I_{s c}, V_{m p}$ and $I_{m p}$ of one module of PV array are 64.2V, 5.96A, 54.7V and 5.58A, respectively. A three-phase $P i$ section line of $15 \mathrm{~km}$ length is chosen as a distribution network. A 5MW, 100VAR load is connected to the distribution network.

\subsection{Without Considering Any Fault}

Initially all the parameters are analyzed at grid without a fault in the distribution network. The DC voltage delivered by boost converter is given in Fig. 8. Fig. 9 shows the voltage delivered by PV inverter after filtering. Figs. 10 and 11 show the three- phase voltage and current generated at the grid. Figs. 12 and 13 give the idea about active and reactive power injected to the grid. Fig. 8 depicts that at $1000 \mathrm{~W} / \mathrm{m}^{2}$ solar irradiance, the PV array generates voltage of about $321 \mathrm{~V}$. The boost converter is increasing voltage from PV natural voltage to $1200 \mathrm{~V}$ DC voltage. Fig. 9 shows the curve of output 
voltage of inverter after it passes through filter. The conversion of sinusoidal AC voltage to the boosted DC voltage is done by 2-level, 3-phase voltage source inverter. For filtering harmonics that are produced by VSI, the sinusoidal LC filter of the series inductance branch of $10 \mathrm{mH}$ with internal resistance $1 \Omega$ and $100 \mu \mathrm{F}$ capacitor banks is used. Fig. 10 depicts about 3-phase voltage injected to grid. Inverter voltage is stepped up by using a delta/star transformer before the grid which boosts up the voltage nearer to the grid voltage. A 3-phase voltage of magnitude $8 \mathrm{KV}$ is injected to the grid. Fig. 11 depicts about the behavior of 3-phase current injected to the grid. Some transients are seen in the beginning, which can be avoided by optimizing the value of the filter components. After $0.1 \mathrm{sec}$, three- phase current of 6 ampere flows to the grid. Fig. 12 depicts that $0.06 \mathrm{MW}$ of active power injected to the grid. Initially transients are seen up to a certain instant of time that is $0.15 \mathrm{sec}$. Then because of the controlling action after $0.15 \mathrm{sec}$, the power injected to the grid is stable.

Fig. 13 depicts about the variation of reactive power at different time interval. As $I_{\text {qref }}$ was set to zero, thus the reactive power during different time interval is zero independent of irradiance. Initially PV draws reactive power from the grid up to $0.15 \mathrm{sec}$, there after it is zero because of the control strategy. According to the IEEE Standard 9292000, THD of grid current and voltage must lie within $5 \%$. Fig. 14 indicates that the total harmonic distortion (THD) of the grid current $0.28 \%$ which is smaller than $5 \%$.Also, the Fig. 15 shows that the total harmonic distortion (THD) of the grid voltage $0.26 \%$ that is smaller than $5 \%$ as recommended in IEEE standard. Fig. 16 depicts about the variation of active and reactive power with change in irradiance. It is observed that with the increase in irradiance from 400 to $1400 \mathrm{w} / \mathrm{m}^{2}$ in steps of $200 \mathrm{w} / \mathrm{m}^{2}$ at time instants of $0,0.5,1.0,1.5,2.0$ and $2.5 \mathrm{sec}$, respectively, the active power as well as reactive power flow to the grid also increases. Fig. 17 depicts about the variation of active and reactive power with change in temperature. With step change in temperature from 20 to $80^{\circ} \mathrm{C}$ in steps of $20^{\circ} \mathrm{Cat}$ time instants of $0,0.5,1.0$ and $1.5 \mathrm{sec}$, respectively, $P$ and $Q$ both are decreasing slightly. The step change in the temperature affects the active power as well as reactive power flow to the grid.

\subsection{Fault Analysis}

Though there are many ways to check the transient state stability of the system, only few factors are taken into account. Next section depicts about the dynamic performance of the plant. Here the system is tested under the worst fault conditions i.e. the symmetrical fault in A.C side and unsymmetrical fault. Fault analysis is performed on grid connected PV system in MATLAB/Simulink to analyze the dynamic behavior of the system. PV system behavior during faulted conditions is also investigated. For the purpose of fault analysis, a three-phase line-to- ground symmetrical fault and unsymmetrical faults are introduced on the grid side of the PV system.

\section{Line to Line to Line to Ground Fault (LLLG Fault)}

Three phases to ground fault is a very common fault in industrial environment which is in fact very dangerous for the power electronics based converters. Because of the fast response of the semiconductor devices the voltage dip and over current flow have to be controlled to avoid any damage to the devices. The results of grid-connected PV system with a LLLG fault are shown below in Fig. 18. At $t=0.3 \mathrm{sec}$ to 0.4 sec, LLLG fault is introduced in the distribution network. DC voltage delivered by the boost converter with LLLG fault is also shown in Fig. 18. Figs. 19 and 20 show 3-phase current and voltage, respectively, at grid with LLLG fault. Figs. 21 and 22 indicate the variation of active and reactive power injected to the grid, respectively, during and after faulted period. The DC voltage delivered by the DC converter is disturbed during the LLLG fault from $0.3 \mathrm{sec}$ to $0.4 \mathrm{sec}$ is shown in Fig. 18. The controller has the ability to control the disturbance, so that just after $0.4 \mathrm{sec}$ the voltage reaches its steady state value which is $1200 \mathrm{~V}$. At $0.3 \mathrm{sec}$ DC voltage rises suddenly from $1200 \mathrm{~V}$ to $1600 \mathrm{~V}$ and then decreases to $1100 \mathrm{~V}$ before clearance of the fault.

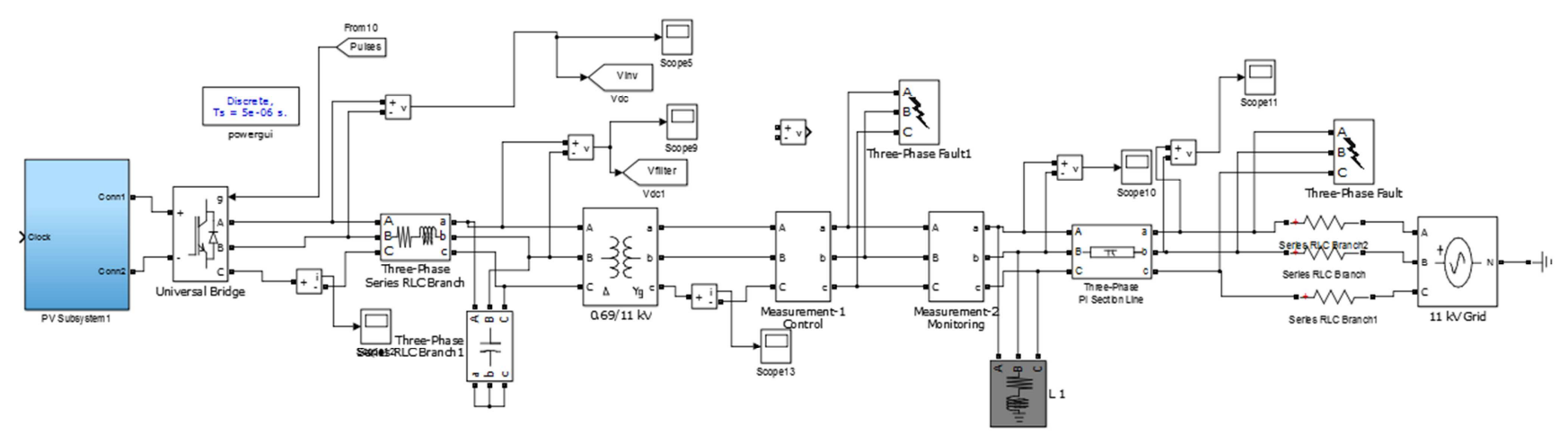

Fig. 7. Simulink diagram of grid connected PV system.

The Fig. 7 shows the Simulink diagram of the proposed system. The PV sub-system consists of PV array, MPPT and boost converter is connected to grid through three phase PWM inverter. The step up transformer is used to increase the voltage to the level of grid. Table 2 gives the data of the system parameters and specifications used for the analysis of the system. 
Table 2. System parameter and specifications.

\begin{tabular}{llll}
\hline Parameter & Values & Parameter & Values \\
\hline Grid voltage & $11 \mathrm{KV}$ & $\mathrm{V}_{\mathrm{dc}}$ & $1200 \mathrm{~V}$ \\
Fs (Fundamental frequency) & $50 \mathrm{hz}$ & Fsw_inv & $2 \mathrm{khz}$ \\
Filter Inductor & $10 \mathrm{mH}$ & Filter Capacitor & $100 \mu \mathrm{F}$ \\
Inverter output voltage before filtering & $1200 \mathrm{~V}$ & Inverter output voltage after filtering & $800 \mathrm{~V}$ \\
Three phase $P i$ section line & $15 \mathrm{~km}$ length & Load & $5 \mathrm{MW}, 100 \mathrm{VAR}$ \\
\hline
\end{tabular}

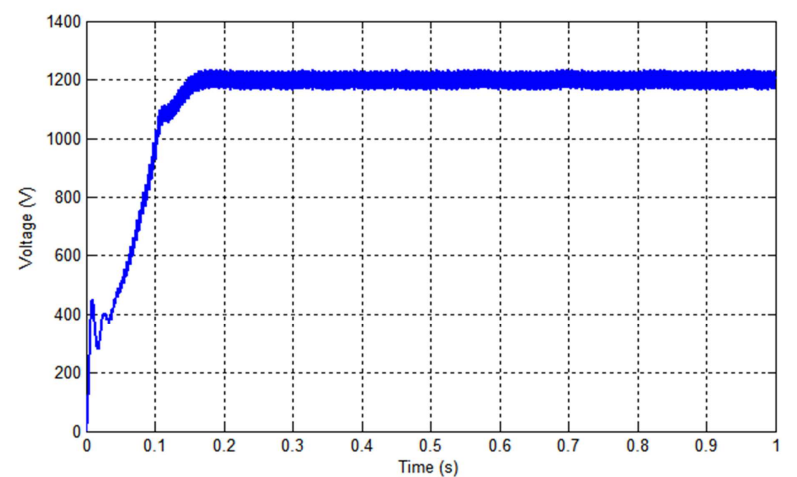

Fig. 8. DC voltage delivered by the boost converter.

Fig. 8 depicts about DC voltage generated by boost converter. At $1000 \mathrm{~W} / \mathrm{m}^{2}$ solar irradiance, the boost converter is increasing voltage of PV natural voltage $321 \mathrm{~V}$ to $1200 \mathrm{~V}$ DC voltage.

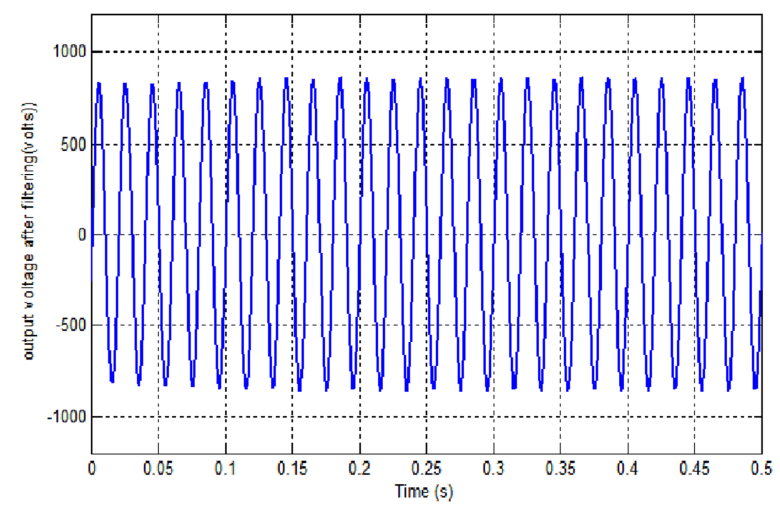

Fig. 9. Inverter output voltage after filtering.

Fig. 9 shows the filtered output voltage of inverter. Here LC filter is used to damp out the harmonics produced by Voltage source inverter.

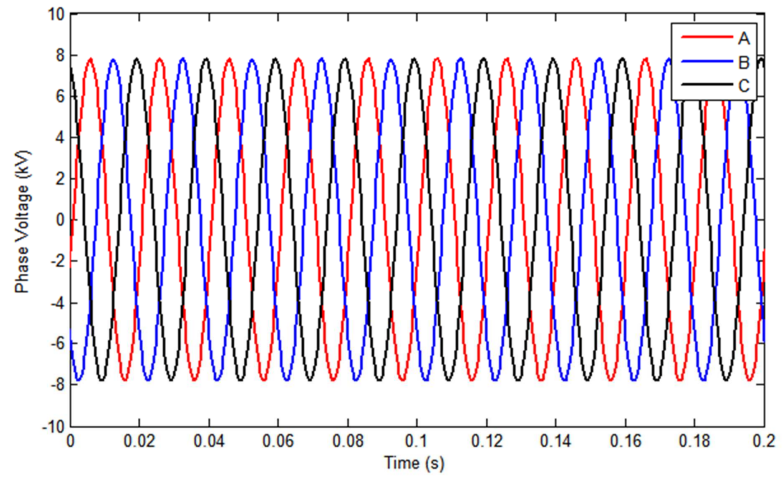

Fig. 10. Three-phase voltage at the grid.
Fig. 10 depicts that 3 -phase voltage of magnitude $8 \mathrm{KV}$ is injected to grid.

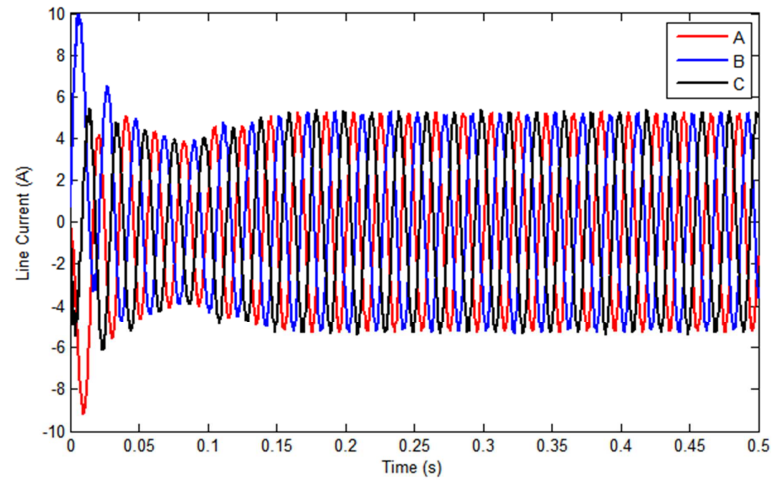

Fig. 11. Thee-phase current at the grid.

Fig. 11 depicts that the 3-phase current of magnitude 6 ampere is injected to the grid.

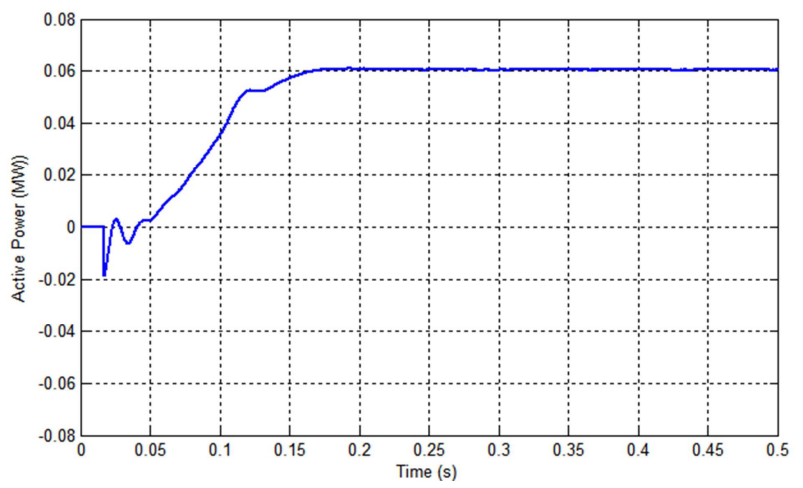

Fig. 12. Active power injected to the grid.

Fig. 12 depicts that $0.06 \mathrm{MW}$ of active power is injected to the grid.

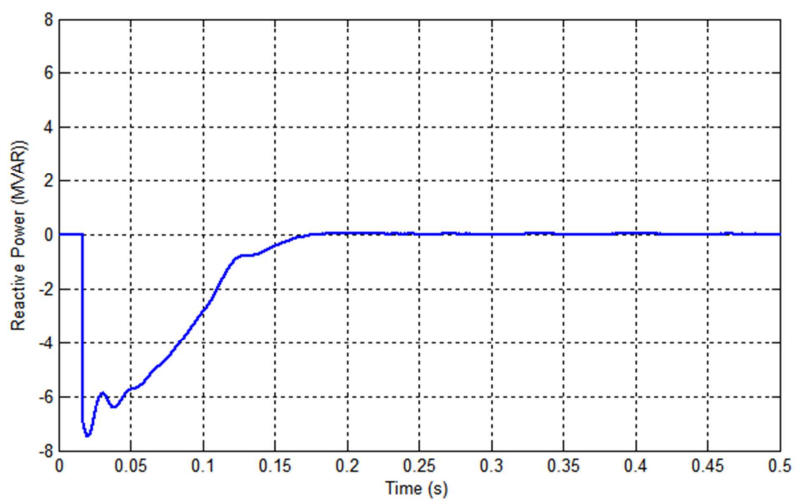

Fig. 13. Reactive power injected to the grid. 
Fig. 13 depicts about the variation of reactive power at different time interval.

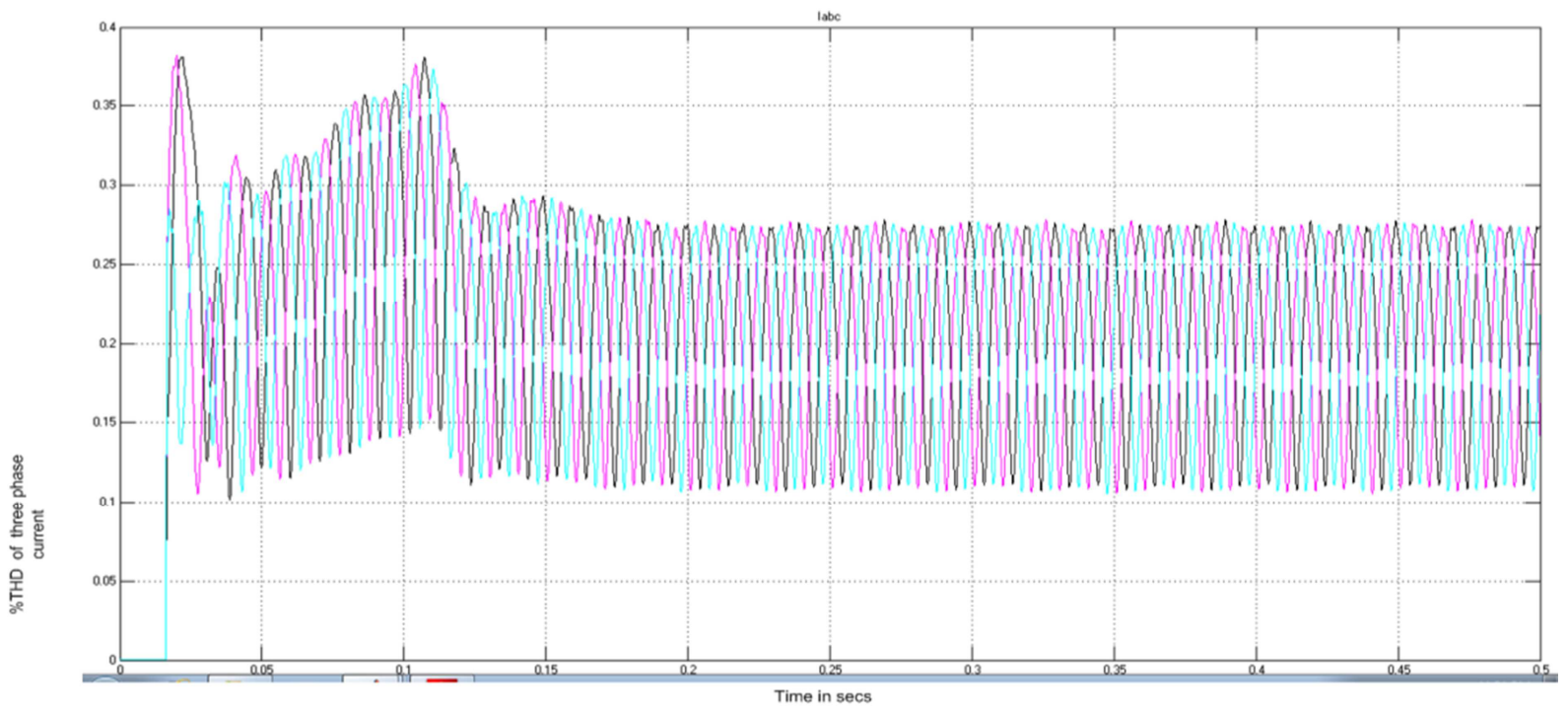

Fig. 14. THD analysis of grid current.

Fig. 14 indicates that the THD analysis of the three phase grid current which is $0.28 \%$.

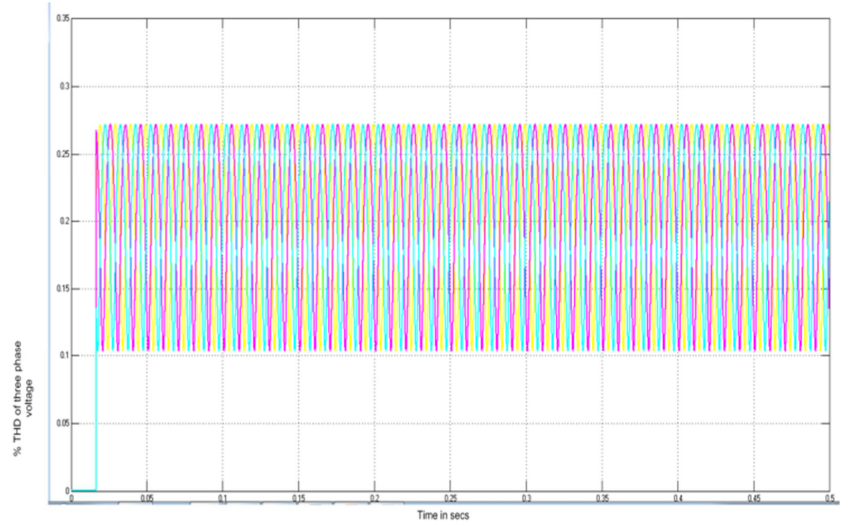

Fig. 15. THD analysis of grid voltage.

Fig. 15 indicates that the THD analysis of the three phase grid voltage which is $0.26 \%$.

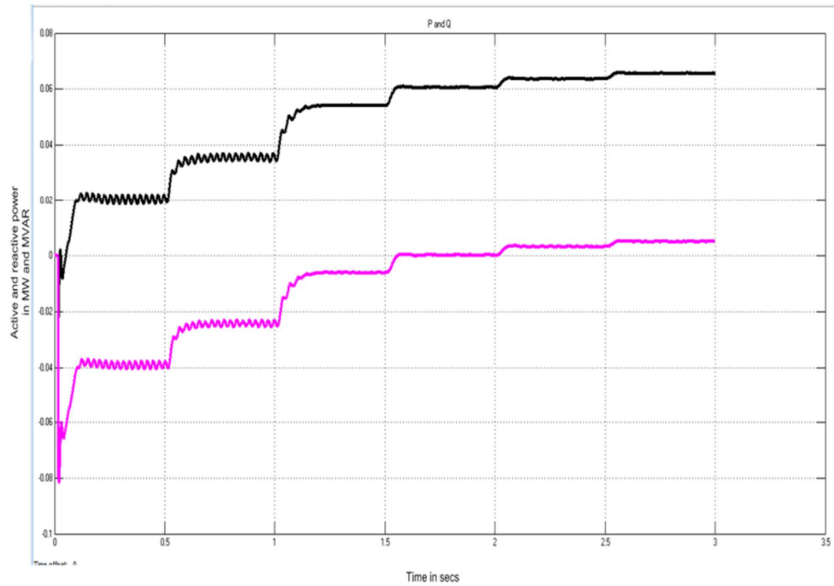

Fig. 16. Effect of change in irradiance on $P$ and $Q$.
Fig. 16 depicts about the variation of active and reactive power with the change in irradiance.

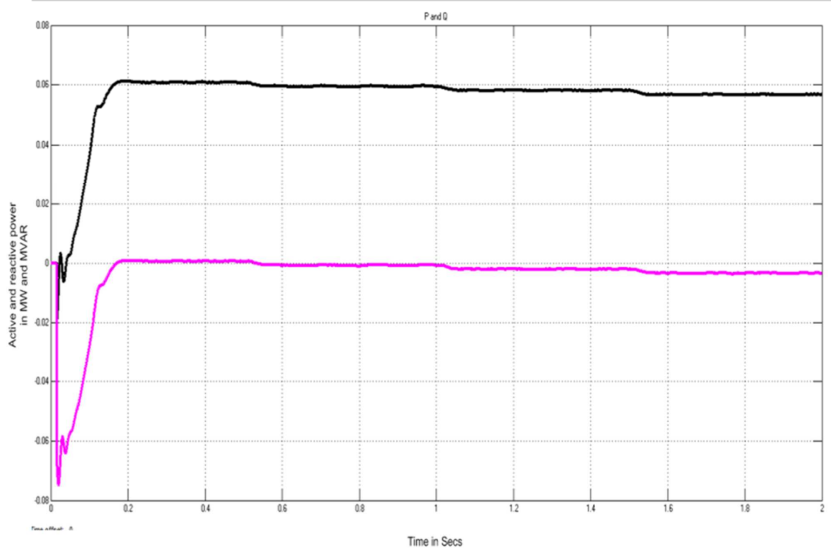

Fig. 17. Effect of change in temperature on $P$ and $Q$.

Fig. 17 depicts about the variation of active and reactive power with change in temperature.

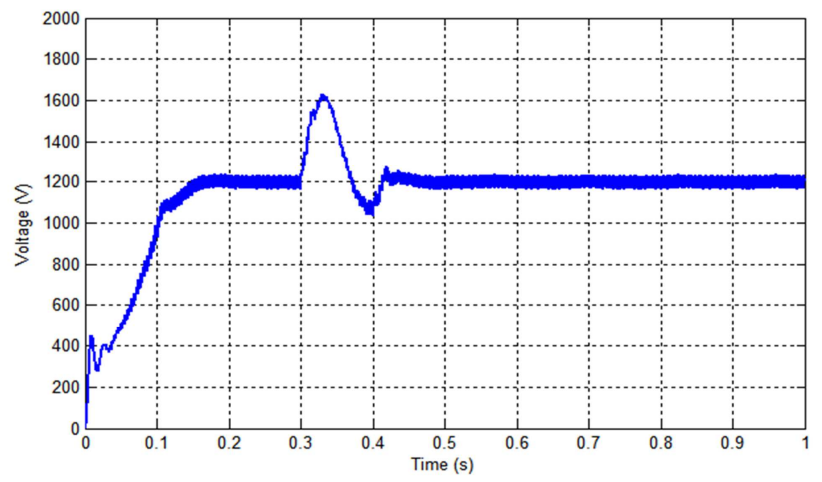

Fig. 18. DC voltage delivered by the boost converter with LLLG fault. 
Fig. 18 shows the disturbance in DC voltage generated by boost converter with the addition of LLLG fault at time 0.3 to $0.4 \mathrm{sec}$.

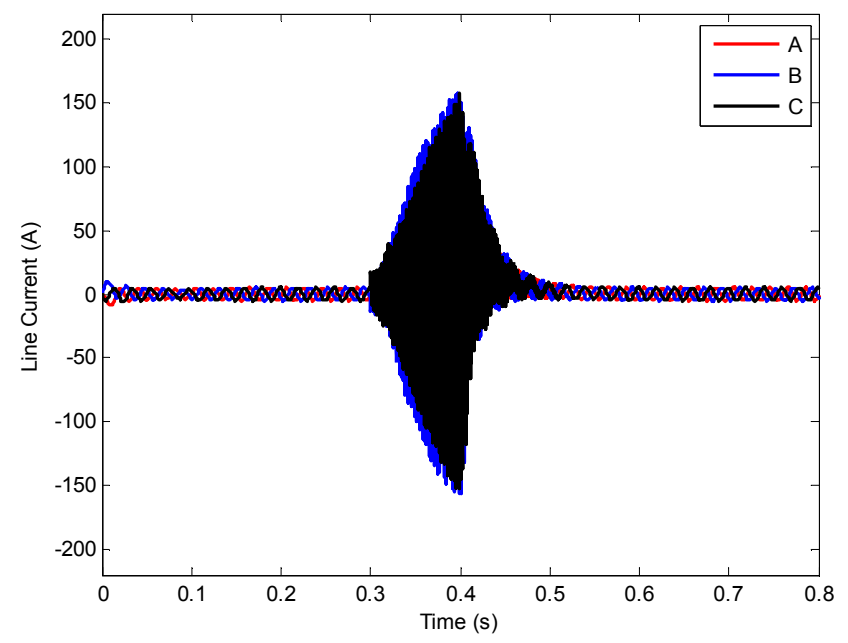

Fig. 19. Three-phase current at the grid with LLLG fault.

Fig. 19 shows the behavior of three phase current during LLLG fault.

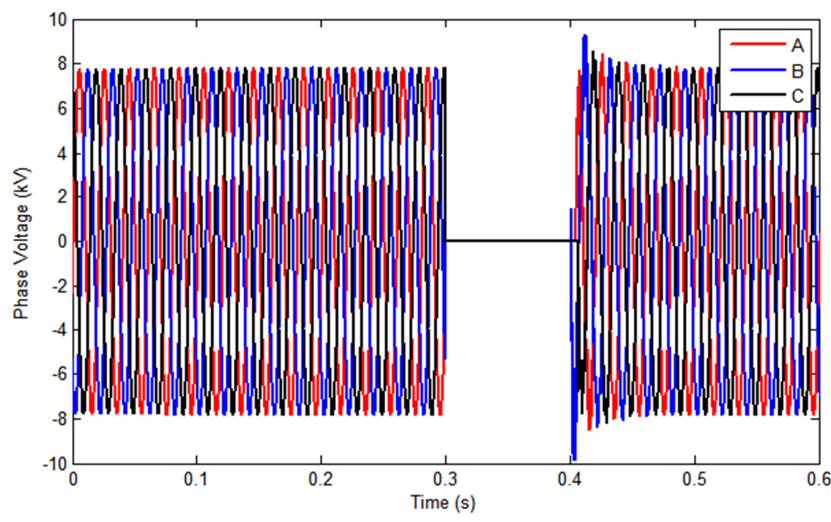

Fig. 20. Three-phase voltage at the grid with LLLG fault.

Fig. 20 depicts that during LLLG fault, three-phase voltage at the grid is zero.

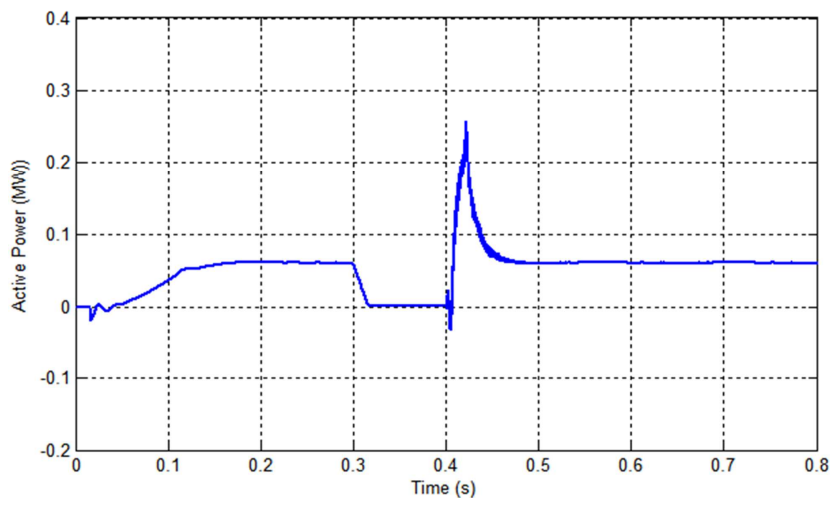

Fig. 21. Active power at the grid with $L L L G$ fault.

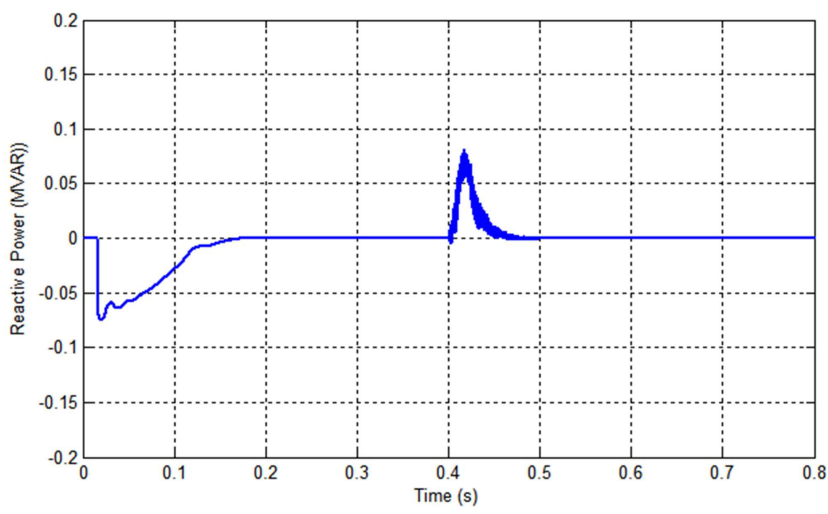

Fig. 22. Reactive power at the grid with LLLG fault.

Figs. 21 and 22 show the disturbances in active power and reactive power injected to the grid during fault period.

The behavior of three-phase current during LLLG fault is shown in figure 19 which indicates that before the initiation of the fault, the current is settled at $5 \mathrm{~A}$ and with the injection of fault at $0.3 \mathrm{sec}$, the current increases to 200A. Finally the current returns to its normal value of $5 \mathrm{~A}$ after the faulted period. The result shows that current initially rises suddenly to $200 \mathrm{~A}$ during the faulted period before reducing to the steady state at a time instant of approximately $0.5 \mathrm{sec}$. Fig. 20 depicts about the behavior of three-phase voltage during LLLG fault. Before the initiation of the fault, the voltage is maintained at $8 \mathrm{kV}(\max )$. During the LLLG fault, the voltage at grid is zero for 0.3 to $0.4 \mathrm{sec}$. After $0.4 \mathrm{sec}$, the voltage settled to its normal value. The result shows that the inverter is shut down during the period from 0.3 to $0.4 \mathrm{sec}$. Active power injected to the grid during faulted period is shown in Fig. 21.From the practical experiences as well as from the simulation it is shown that the real and reactive power injected to the grid are also disturbed during the LLLG fault during the period from $0.3 \mathrm{sec}$ to $0.4 \mathrm{sec}$. During the faulted period the active power injected to the grid is zero. It is also visible that a power surge occurs just after the fault clearance, which enforces the converter to carry more power which puts stress on the devices. Fig. 22 depicts about the variation of reactive power during the faulted period. The result shows that reactive power is a less disturbed parameter among all other parameters. Just after the clearance of the fault a surge is seen, then after $0.5 \mathrm{sec}$ it settled to its normal value.

\section{Conclusion}

In this paper, a modified current control strategy based on MATLAB/Simulink has been studied for PV system which is connected to $11 \mathrm{KV}$ grid. The variation of three-phase current, voltage, active power, reactive power injected to the grid at different time intervals are studied. The mathematical model of the converter is based upon the $d-q$ reference frame. A three-phase voltage source inverter is regulated to inject maximum real power into the grid in the synchronously rotating frame. The correctness of the proposed current control technique is proved by the given simulation results. The simulation results depict that the proposed controller 
ensures the global stability, fast tracking of DC bus voltage with zero steady state error, rejection of exogenous inputs generally known as disturbances and robustness against the parametric uncertainties. To justify the control design several kind of faults and case studies are done. Due to the robustness of the controller, just after the fault the system parameters regain their original values. The simulation results confirmed the effectiveness of the implemented control schemes, since the generated real and reactive powers follow the reference values furnished by the MPPT control of the photovoltaic system both in normal and perturbed operation.

\section{References}

[1] G. Farivar, B. Asaei, "A New Approach for Solar Module Temperature Estimation using the Simple Diode Model", IEEE Transactions on Energy Conversion, Vol.26, No.4, Dec. 2011, pp.1118-1126.

[2] M. F. Schonardie, D. C. Martins, "Application of the $d q 0$ Transformation in the Three-Phase Grid-Connected PV Systems with Active and Reactive Power Control", IEEE International Conference on Sustainable Energy Technologies, Singapore, 2008, pp. 18-23.

[3] W. Cai, H. Ren, Y. Jiao, M. Cai, X. Cheng, "Analysis and Simulation for Grid-Connected Photovoltaic System based on MATLAB," International Conference on Electrical and Control Engineering (ICECE), Yichang, 2011, pp.63-66.

[4] A. Yazdani, P. P. Dash, "A Control Methodology and Characterization of Dynamics for a Photovoltaic (PV) System Interfaced with a Distribution Network" IEEE Transactions on Power Delivery, Vol.24, No.3, July 2009, pp.1538-1551.

[5] F. Blaabjerg, R. Teodorescu, M. Liserre, A. V. Timbus, "Overview of Control and Grid Synchronization for Distributed Power Generation Systems", IEEE Transactions on Industrial Electronics, Vol.53, No.5, Oct. 2006, pp.13981409.

[6] R. Sunny, R. Anto, "Harmonics Control and Performance Analysis of a Grid-Connected Photovoltaic System", International Conference on Advanced Computing and Communication Systems (ICACCS), Coimbatore, 2013, pp. 16.

[7] Z. Dejia, Z. Zhengming, M. Eltawil, Y. Liqiang, "Design and
Control of a Three-Phase Grid-Connected Photovoltaic System with Developed Maximum Power Point Tracking", Twenty-Third Annual IEEE Applied Power Electronics Conference and Exposition, Austin, TX, 2008, pp.973-979.

[8] S. Meshram, G. Agnihotri, S. Gupta, "An Efficient Constant Current Controller for PV Solar Power Generator Integrated with the Grid", Fifth IEEE Power India Conference, Murthal, 2012, pp.1-6.

[9] S. B. Kjaer, J. K. Pedersen, F. Blaabjerg, "A Review of SinglePhase Grid-Connected Inverters for Photovoltaic Modules", IEEE Trans. Ind Appl., Vol.41, No.5, Sep./Oct. 2005, pp.1292-1306.

[10] J. M. Carrasco, L. G. Franquelo, J. T. Bialasiewicz, E. Galvan, R. C. P. Guisado, M. A. M. Prats, J. I. Leon, N. MorenoAlfonso, "Power Electronic Systems for the Grid Integration of Renewable Energy Sources: A survey", IEEE Trans.on Ind. Electron, Vol.53, No.4, Aug. 2006, pp.1002-1016.

[11] J. H. R. Enslin, P. J. M. Heskes, "Harmonic Interaction between a Large Number of Distributed Power Inverters and the Distribution Network", IEEE Trans. on Power Electron, Vol.19, No.6, Nov. 2004, pp.1586-1593.

[12] N. Srisaen, A. Sangswang, "Effect of PV Grid-Connected System Location on a Distribution System", Proc. Of IEEE Asia Pacific Conf. on Circuit and Systems, Dec. 2006, pp.852-855.

[13] B. K. Naik, M. Das, T. K. Chatterjee, K. Chatterjee, "Study and implementation of synchronization algorithm in three phase grid connected PV system", 3rd International Conference on Recent Advances in Information Technology (RAIT), Dhanbad, 2016, pp.304-309.

[14] Y. Teng, C. Xiong, C. Li, Z. Zhang, X. Yu, W. Zhang, "Study on harmonic and reactive current detection in grid-connected $P V$ Power stations", IEEE International Conference on Progress in Informatics and Computing (PIC), Nanjing, 2015, pp. 433-437.

[15] S. A. Lakshmanan, A. Jain, B.S. Rajpurohit, "Grid voltage monitoring techniques for single phase grid connected solar $P V$ system", IEEE 6th India International Conference on Power Electronics (IICPE), Kurukshetra, 2014, pp.1-6.

[16] P. A. Pattanaik, N. K. Pilli, S. K. Singh, "Design, simulation \& performance evaluation of three phase grid connected $P V$ panel," IEEE Power, Communication and Information Technology Conference (PCITC), Bhubaneswar, 2015, pp.195-200. 